\title{
Superação da dormência de sementes de Brachiaria brizantha cv. "Marandu"
}

\section{Seed dormancy-breaking of Brachiaria brizantha cv. Marandu}

\author{
Maria Juliana Ribeiro Lacerda'; Juliana Silva Rodrigues Cabral'2; \\ Juliana de Fátima Sales ${ }^{3 *}$; Karina Rocha Freitas ${ }^{4}$; Antônio João Fontes ${ }^{5}$
}

\section{Resumo}

O objetivo deste trabalho foi avaliar métodos de superação da dormência de sementes de Brachiaria brizantha cv. Marandu. O experimento foi conduzido no Laboratório de Sementes do IFGoiano - Campus Rio Verde. Foi utilizado o delineamento inteiramente casualizado, com oito tratamentos: 1) testemunha; 2) imersão em ácido giberélico $\left(100 \mathrm{mgL}^{-1}\right)$ por $48 \mathrm{~h}$; 3$)$ imersão em ácido giberélico $\left(200 \mathrm{mgL}^{-1}\right)$ por $48 \mathrm{~h}$; 4) imersão em ácido sulfúrico concentrado por 5 min.; 5) imersão em ácido sulfúrico concentrado por 10 min.; 6) imersão em água fervente por 1 min.; 7) imersão em água fervente por 2 min.; 8) imersão em água fervente por $3 \mathrm{~min}$, com 4 repetições de 50 sementes. Diariamente, foram realizadas as avaliações de germinação, para determinar o Índice de Velocidade da Germinação e, após a completa estabilização da germinação (25 dias), foi quantificada a porcentagem de germinação. Os tratamentos com água fervente, independentemente do tempo de imersão das sementes, foram os mais efetivos para superar a a dormência de sementes de Brachiaria brizantha cv. Marandu.

Palavras-chave: Germinação, pastagem, ácido sulfúrico, ácido giberélico

\begin{abstract}
This work aimed to evaluate methods to breaking seed dormancy of Brachiaria brizantha cv. Marandu. An experiment was carried out at the Laboratory of Seeds from Instituto Federal Goiano - Campus Rio Verde. A completely randomized design with eight treatments to breaking seed dormancy was used. The treatments were: 1) control; 2) immersion in gibberellic acid (100 $\left.\mathrm{mg} \mathrm{L}^{-1}\right)$ for $48 \mathrm{~h} ; 3$ ) immersion in gibberellic acid $\left(200 \mathrm{mg} \mathrm{L}^{-1}\right)$ for $48 \mathrm{~h}$; 4) immersion in concentrated sulphuric acid for $\left.5 \mathrm{~min} ; 5\right)$ immersion in concentrated sulphuric acid for $10 \mathrm{~min}$; 6) immersion in hot water $\left(100{ }^{\circ} \mathrm{C}\right)$ for $1 \mathrm{~min}$; 7) immersion in hot water $\left(100^{\circ} \mathrm{C}\right)$ for 2 min and 8$)$ immersion in hot water $\left(100^{\circ} \mathrm{C}\right)$ for 3 min with four replicates. Daily, germination was evaluated to determine the germination speed index. After the complete germination ( 25 days), the seed germination percentage was quantified. Hot water treatments, independently of the seed immersion time, were the most effective to breaking the seed dormancy of $B$. brizantha cv. Marandu.
\end{abstract}

Key words: Germination, grass pasture, hot water, gibberellic acid

${ }^{1}$ Zootecnista, Mestranda do Curso de Pós-Graduação em Ciência Animal da Universidade Federal de Goiás, Goiânia-GO. E-mail: juliana_lacerdas@yahoo.com.br

${ }^{2}$ Tecnóloga em Produção de Grãos, Mestranda em Ciências Agrárias do Instituto Federal de Educação, Ciência e Tecnologia Goiano, Campus Rio Verde, Rio Verde, GO. E-mail: jsrcabral@gmail.com

${ }^{3}$ Bióloga, Doutora em Fitotecnia, Professora do Instituto Federal de Educação, Ciência e Tecnologia Goiano, Campus Rio Verde, Rio Verde, GO. E-mail: julianacefetrv@yahoo.com.br

${ }^{4}$ Zootecnista, Doutora em Ciência Animal, Professora do Instituto Federal de Educação, Ciência e Tecnologia do Estado de Goiás, Campus Inhumas, Inhumas, GO. E-mail: freitaskk@yahoo.com.br

${ }^{5}$ Zootecnista, Mestre em Produção Animal, Professor do Instituto Federal de Educação, Ciência e Tecnologia Goiano, Campus Rio Verde, Rio Verde, GO. E-mail: fontes2.rv@ifgoiano.edu.br

* Autor para correspondência 


\section{Introdução}

Cerca de $80 \%$ das áreas de pastagens brasileiras apresentam algum grau de degradação. Uma das causas é a baixa taxa de germinação de sementes de espécies forrageiras. É conhecido que algumas sementes não germinam mesmo quando submetidas à condições ambientais consideradas favoráveis, sendo as mesmas classificadas como dormentes.

A dormência é um tipo de latência em que a ausência de germinação é causada por empecilhos localizados na própria semente. É imposta pela combinação de condições especificas do ambiente, provocando a interferência de um ou mais mecanismos de bloqueio, impedindo a transcrição da mensagem genética para a ativação da seqüência metabólica que culmina com a germinação. Assim, os eventos iniciais após a embebição em sementes dormentes, dependem da informação genética já existente durante o período de maturação, ou seja, anteriormente ao início do repouso fisiológico (MARCOS FILHO, 2005).

A dormência de sementes é peculiar para cada espécie vegetal. Por isso, não é possível generalizar sobre suas causas, que podem ocorrer isoladamente ou combinadas, como ocorrem com as gramíneas forrageiras (TOLEDO; CHAMMA; NOVEMBRE, 1995). Existem bloqueios de natureza fotoquímica ou bioquímica (dormência fisiológica), de natureza difusa (dormência física) e de natureza morfológica (dormência morfológica). O fenômeno da dormência dificulta o estabelecimento uniforme das populações e favorece o surgimento de plantas daninhas nas áreas de pastagens (MARTINS; SILVA, 2003; LAURA et al., 2005).

A produção de sementes de Brachiaria brizantha apresenta, além de desuniformidade na maturação e na degrana, dormência nas sementes cuja natureza, intensidade e persistência não estão suficientemente esclarecidas (MARTINS; SILVA, 2003).

São comumente utilizados vários tipos de tratamentos: térmico, escarificação química, mecânica, peletização, e polimerização que têm sido empregados para a superação da dormência das sementes de Brachiaria brizantha cv. Marandu (SENRA et al., 2005). A escarificação das sementes proporciona redução de dormência pela danificação de estruturas externas, seja por meio do uso de ácido sulfúrico $\left(\mathrm{H}_{2} \mathrm{SO}_{4}\right)$ concentrado ou de máquinas específicas (GARCIA; CÍCERO, 1992).

Alguns métodos são recomendados para a superação total da "dureza" das sementes, como os tratamentos químicos, escarificação mecânica e tratamentos térmicos com o uso de temperaturas elevadas. A eficiência de cada tratamento é variável segundo a espécie. Espécies de clima tropical respondem mais a métodos onde é utilizada a exposição ao calor, visto que tratamentos de superação de dormência devem simular as condições ambientais pelas quais passam as sementes em seu "habitat" natural (GARCIA; BASEGGIO, 1999). A escarificação química, método redutor de dormência usado na maioria dos lotes de sementes de $B$. brizantha comercializados nas exportações, apresenta riscos operacionais aos trabalhadores, polui o ambiente e, além disso, pode promover danos qualitativos às sementes. Pesquisas que avaliam a superação da dormência em sementes de gramíneas forrageiras têm considerado a ação de temperaturas elevadas (MAEDA; PEREIRA; MEDINA, 1997). Entretanto, ainda há dúvidas relacionadas à quantidade de calor necessária para as diferentes espécies.

Além de superar a dormência, o tratamento térmico também tem sido utilizado amplamente como um novo método de erradicação de patógenos do material vegetal, visando à redução do uso de pesticida (TENENTE et al., 2005). Isto minimiza os riscos de introdução de novas espécies em áreas isentas, além de beneficiar agricultores que poderão utilizar-se dessa técnica como medida preventiva e curativa de patógenos associadas as sementes.

Goedert (1985) relatou a eficiência da aplicação de compostos químicos na superação de dormência 
de B. decumbens. Além disso, o autor revelou que a eficiência da escarificação de sementes de braquiárias com ácido sulfúrico pode apresentar resultados variáveis conforme a espécie.

O objetivo deste trabalho foi avaliar métodos de superação da dormência de sementes de Brachiaria brizantha $\mathrm{cv}$. Marandu.

\section{Material de Métodos}

O experimento foi conduzido no Laboratório de Sementes do Instituto Federal de Educação, Ciência e Tecnologia Goiano - Campus Rio Verde. Foi utilizado um delineamento inteiramente casualizado, com oito tratamentos: 1) testemunha; 2) imersão em ácido giberélico $\left(100 \mathrm{mgL}^{-1}\right)$ por $48 \mathrm{~h}$; 3) imersão em ácido giberélico $\left(200 \mathrm{mgL}^{-1}\right)$ por $48 \mathrm{~h}$; 4) imersão em $\left(\mathrm{H}_{2} \mathrm{SO}_{4}\right)$ concentrado por 5 min.; 5) imersão em $\left(\mathrm{H}_{2} \mathrm{SO}_{4}\right)$ concentrado por 10 min.; 6) imersão em água fervente por 1 min.; 7) imersão em água fervente por 2 min.; 8) imersão em água fervente por $3 \mathrm{~min}$. Cada tratamento constou de quatro repetições com 50 sementes por parcela. Estas foram acondicionadas em caixas de acrílico do tipo "gerbox" transparentes.
As sementes de Brachiaria brizantha cv. Marandu após submetidas aos tratamentos, foram distribuídas sobre duas folhas de papel germitest umedecido com água destilada, 2,5 vezes o peso do substrato seco, e armazenadas nas caixas de acrílico tipo "gerbox". Em seguida, foram colocadas em germinadores tipo "Mangelsdorf" regulados à temperatura constante de $25{ }^{\circ} \mathrm{C}$. Diariamente, foram realizadas as avaliações de germinação, sendo consideradas germinadas as sementes que apresentaram início de protrusão com $5 \mathrm{~mm}$ de radícula, a fim de calcular-se o Índice de Velocidade da Germinação (IVG) (MAGUIRE, 1962) e, após a completa estabilização da germinação (25 dias), foi quantificada a percentagem de germinação. Os dados foram submetidos à análise de variância e as médias comparadas pelo teste Tukey (5\%).

\section{Resultados e Discussão}

Foi verificado que os tratamentos mais efetivos na superação da dormência foram aqueles que utilizaram água fervente, independentemente do tempo de imersão, onde foi constatado maior percentual de germinação (Tabela 1). Também não foi observada eficácia dos tratamentos com ácido giberélico e $\mathrm{H}_{2} \mathrm{SO}_{4}$, já que os mesmos não diferiram do tratamento testemunha (Tabela 1).

Tabela 1. Germinação de sementes de Brachiaria brizantha cv. Marandu submetidas a diferentes tratamentos para superação de dormência.

\begin{tabular}{lc}
\hline \multicolumn{1}{c}{ Tratamentos } & Germinação (\%) \\
\hline Testemunha & $3,75 \mathrm{~b}^{1}$ \\
Ácido giberélico $\left(100 \mathrm{mgL}^{-1}\right)$ & $6,00 \mathrm{~b}$ \\
Ácido giberélico $\left(200 \mathrm{mgL}^{-1}\right)$ & $3,50 \mathrm{~b}$ \\
Ácido sulfúrico concentrado $(5 \mathrm{~min})$ & $6,00 \mathrm{~b}$ \\
Ácido sulfúrico concentrado $(10 \mathrm{~min})$ & $6,62 \mathrm{~b}$ \\
Água fervente $(1 \mathrm{~min})$ & $74,75 \mathrm{a}$ \\
Água fervente $(2 \mathrm{~min})$ & $85,37 \mathrm{a}$ \\
Água fervente $(3 \mathrm{~min})$ & $74,75 \mathrm{a}$ \\
\hline
\end{tabular}

${ }^{1}$ Médias seguidas da mesma letra não diferem entre si pelo teste Tukey ao nível de $5 \%$ de probabilidade. C.V $(\%)=27,88$. DMS $=4,57$. Média geral=32,59. 
Estudos feitos por Garcia e Cícero (1992) constataram que, o melhor tratamento para superação da dormência das sementes de Brachiaria brizantha cv. Marandu foi a associação de $\mathrm{H}_{2} \mathrm{SO}_{4}$ concentrado e nitrato de potássio $(0,2 \%)$ por $15 \mathrm{~min}$. Martins e Silva (2001) avaliando o comportamento da dormência de sementes de braquiárias observaram que a imersão em água aquecida a $70{ }^{\circ} \mathrm{C}$ por $10 \mathrm{a}$ $15 \mathrm{~h}$ reduziu a taxa de dormência. Igualmente, o aquecimento a $85^{\circ} \mathrm{C}$ e imersão em $\mathrm{H}_{2} \mathrm{SO}_{4}$ reduziram a dormência e causaram efeitos positivos imediatos no desempenho germinativo das sementes.

Já Senra et al. (2005) relataram um incremento no percentual de germinação de sementes de Brachiaria brizantha cv. Marandu nos tratamentos com escarificação mecânica $(74,7 \%)$ e química $(72,6 \%)$. Neste trabalho, foi obtido um percentual de germinação equivalente a $85,37 \%$ com água fervente por $2 \mathrm{~min}$. Tal método é mais prático e mais econômico que qualquer tipo de escarificação química ou mecânica, sendo uma alternativa de uso ao produtor rural.

Câmara e Stacciarini-Seraphin (2002), trabalhando com Brachiaria brizantha $\mathrm{cv}$. Marandu constataram que as sementes apresentaram baixo percentual de germinação quando tratadas com ácido giberélico. Enquanto que Dantas et al. (2001), observaram maior porcentagem de germinação de sementes de Capim-marmelada (Brachiaria plantaginea) quando tratadas com ácido giberélico.

De modo similar ao percentual de germinação, os tratamentos com água fervente por 2 e 3 min favoreceram o IVG, superando os demais tratamentos (Tabela 2). Todavia, a água fervente por 2 min superou a imersão em água fervente por 1 min e igualou-se ao tratamento com 3 min. Assim como ocorreu para percentual de germinação, não foi verificada diferença significativa entre os tratamentos com ácido giberélico, $\mathrm{H}_{2} \mathrm{SO}_{4}$ e a testemunha.

Tabela 2. Índice de Velocidade da Germinação (IVG) de sementes de Brachiaria brizantha cv. Marandu submetidas a diferentes tratamentos de superação de dormência.

\begin{tabular}{lc}
\hline \multicolumn{1}{c}{ Tratamentos } & IVG \\
\hline Testemunha & $1,14 \mathrm{c}^{1}$ \\
Ácido giberélico $\left(100 \mathrm{mgL}^{-1}\right)$ & $1,20 \mathrm{c}$ \\
Ácido giberélico $\left(200 \mathrm{mgL}^{-1}\right)$ & $1,17 \mathrm{c}$ \\
Ácido sulfúrico concentrado $(5 \mathrm{~min})$ & $1,25 \mathrm{c}$ \\
Ácido sulfúrico concentrado $(10 \mathrm{~min})$ & $1,20 \mathrm{c}$ \\
Água fervente $(1 \mathrm{~min})$ & $6,92 \mathrm{~b}$ \\
Água fervente $(2 \mathrm{~min})$ & $8,28 \mathrm{a}$ \\
Água fervente $(3 \mathrm{~min})$ & $7,32 \mathrm{ab}$ \\
\hline
\end{tabular}

${ }^{1}$ Médias seguidas da mesma letra não diferem entre si pelo teste Tukey ao nível de $5 \%$ de probabilidade. C.V(\%)=22,99. DMS=0,41. Média geral=3,56.

Alencar (2008) observou que sementes de Brachiaria brizantha Stapf. não encontraram de Stylosanthes macrocephala submetidas a diferença entre os tratamentos de escarificação com temperaturas de $60{ }^{\circ} \mathrm{C}$ por $15 \mathrm{~h}$ apresentaram maior ácido $\mathrm{H}_{2} \mathrm{SO}_{4}$ (concentração comercial por $13 \mathrm{~min}$.) IVG comparadas aos demais tratamentos (50 e 70 mais fungicidas (thiabendazol, captan, thiram e ${ }^{\circ} \mathrm{C}$ em estufa de circulação de ar, por 5 e $10 \mathrm{~h}$ ) e iprodione + thiram), comparado ao $\mathrm{H}_{2} \mathrm{SO}_{4}$ isolado a testemunha. Enquanto que Dias e Toledo (1993) e a testemunha. avaliando a superação de dormência em sementes 


\section{Conclusão}

Os tratamentos com água fervente, independentemente do tempo de imersão das sementes, foram efetivos na superação da dormência de sementes de Brachiaria brizantha cv. Marandu.

\section{Referências}

ALENCAR, K. M. C. Tratamentos pré-germinativos em sementes de Stylosanthes SW. (Leguminosae Papilionoideae). 2008. Dissertação (Mestrado) Fundação Universidade Federal de Mato Grosso do Sul, Campo Grande-MS.

CÂMARA, H. H. L. L.; STACCIARINI-SERAPHIN, E. Germinação de sementes de brachiaria brizantha cv. marandu sob diferentes períodos de armazenamento e tratamento hormonal. Pesquisa Agropecuária Tropical, v. 32, n. 1, p. 21-28, 2002.

DANTAS, B. F.; ALVES, E.; ARAGÃO, C. A.; TOFANELLI, M. B. D.; CORREAA, M. R.; RODRIGUES, J. D.; CAVARIANI, C.; NAKAGAWA. Germinação de sementes de capim-marmelada (brachiaria plantaginea (Link) Hitchc.) tratadas com ácido giberélico. Revista Brasileira de Sementes, Brasília, v. 23, n. 2, p. 27-34, 2001.

DIAS, D. C.F. S.; TOLEDO, F. F. Germinação e incidência de fungos em testes com sementes de Brachiaria brizantha Stapf. Scientia Agricola. Piracicaba, v. 50, n. 1, p. 68-79, 1993.

GARCIA, E. N.; BASEGGIO, J. Poder germinativo de sementes de Desmodium incanum DC. (leguminosae). Revista Brasileira de Agrociência, Pelotas, v. 5, n. 3, p. 199-202, 1999.

GARCIA, J.; CÍCERO, S. M. Superação de dormência em sementes de Brachiaria brizantha cv. Marandu. Scientia Agricola, Piracicaba, v. 49, n. 1, p. 9-13, 1992.

GOEDERT, C. O. Efeitos de reagentes químicos na superação da dormência em sementes de gramíneas forrageiras. In: CONGRESSO BRASILEIRO DE
SEMENTES, 4., 1985, Brasília. Resumos... Brasília, ABRATES, 1985. p. 231-233.

LAURA, V. A.; HARADA, T. N.; CONTIJO NETO, M. M.; DO VALLE, C. B.; KOBAYASHI, A. B. Efeitos do ácido giberélico sobre a germinação de cultivares de Brachiaria humidicola. In: REUNIÃO ANUAL DA SOCIEDADE BRASILEIRA DE ZOOTECNIA, 42., 2005, Goiânia. Resumos... Goiânia, 2005.

MAEDA, J. A; PEREIRA, M. F. D. A.; MEDINA, P. F. Conservação e superação da dormência de sementes de Paspalum notatum Flugge. Revista Brasileira de Sementes, Brasília, v. 19, n. 2, p. 165-171, 1997.

MAGUIRE, J. D. Speed of germination aid in selection and evaluation for seedling and vigour. Crop Science, Madison, v. 2, n. 2, p. 176-177, 1962.

MARCOS FILHO, J. Fisiologia de sementes de plantas cultivadas. Piracicaba: FEALQ, v. 12, 2005. 495 p.

MARTINS, L.; SILVA, W. R. Comportamento da dormência em sementes de braquiária submetidas a tratamentos térmicos e químicos. Pesquisa Agropecuária Brasileira, Brasília, v. 36, n. 7, p. 997-1003, 2001.

Efeitos imediatos e latentes de tratamentos térmico e químico em sementes de Brachiaria brizantha cultivar Marandu. Bragantia, Campinas, v. 62, n. 1, p. 81-88, 2003.

SENRA, A. F.; ZIMMER, A. H.; LEMPP, B.; GONTIJO NETO, M. M.; PEREIRA, M. A. Tratamentos de sementes de "Brachiaria brizantha" cv. Marandu como novas alternativas para o mercado. In: REUNIÃO ANUAL DA SOCIEDADE BRASILEIRA DE ZOOTECNIA, 42., 2005, Goiânia. Resumos...Goiânia, 2005. p. 864-866.

TENENTE, R. C. V.; GONZAGA, V.; SOUSA, A. I.; SANTOS, D. S. Aplicação de tratamentos físicos e químicos em sementes de beterraba importada, na erradicação de Ditylenchus dipsaci. [S.1.]: Embrapa Recursos Genéticos e Biotecnologia, 2005. (Circular Técnica, 36).

TOLEDO, F.F. de; CHAMMA, H.M. C.P.; NOVEMBRE, A. D. L. C. Germinação de sementes de Panicum maximum Jacq. pré-tratadas com ácido sulfúrico. Scientia Agricola, Piracicaba, v. 52, n. 1, p. 20-24, 1995. 
